\title{
¿ES EL CINE JAPONÉS UN CINE NACIONAL?
}

\author{
Is Japanese Cinema a National Cinema? \\ Marcos P. CEnTENo MARTín ${ }^{1}$ \\ SOAS, University of London
}

\section{Resumen}

La construcción del cine japonés como cine nacional ha partido a menudo de una visión esencialista que ha ignorado la dimensión transnacional de esta filmografía. Por un lado, el descubrimiento occidental de ciertos autores japoneses en los años cincuenta condujo a la articulación del paradigma del cine nacional japonés a partir de películas dirigidas a asombrar al público europeo con imágenes exóticas de Japón. Los grandes maestros, Kurosawa, Mizoguchi y Ozu fueron escogidos como representantes de una supuesta japonesidad cinematográfica ignorando el peso de Occidente en sus obras. Por otro lado, el estudio de este corpus tradicionalmente ha evolucionado con herramientas teóricas desarrolladas en Occidente y necesita renovarse con conceptos de la tradición cultural, estética y filosófica propia. Pero además, es necesario evaluar cómo se implementaron los elementos del lenguaje fílmico en Japón para entender su relativismo respecto a la historia general del cine. Sus usos y formas no siempre han coincidido con los desarrollos occidentales, de forma que conceptos fílmicos occidentales no han tenido exactamente el mismo significado en el contexto japonés.

Palabras clave: cine japonés, cine nacional, transnacionalidad teoría fílmica, cine de postguerra

\section{Abstract}

The construction of Japanese cinema as a national cinema has often drawn on a essentialist vision neglecting the transnational nature of this filmography. On the one hand, the Western discovery of certain Japanese authors in the fifties triggered

1 Senior Teaching Fellow in Film Studies and Convenor MA Global Cinemas and the Transcultural. Department of East Asian Languages and Cultures. Centre for Media and Film Studies (SOAS). Correo electrónico: mc100@soas.ac.uk. Fecha de recepción del artículo: 25 de noviembre de 2017. Fecha de aceptación: 22 de enero de 2018. 
the articulation of the paradigm of the Japanese «national cinema» from films aiming to astonish European audiences with exotic images of Japan. The great masters, Kurosawa, Mizoguchi and Ozu, were chosen as main representatives of the apparent cinematographic japaneseness neglecting the weight of the West on their works. On the other hand, the study of this corpus has been traditionally evolved with theoretical tools developed in the West and need a renewal with concepts taken from Japanese philosophical, aesthetic and cultural tradition. Moreover, it is necessary to assess how the film language elements were implemented in Japan in order to understand its relativism regarding the general film history. Their usages and forms were not always equivalent to those in the West and as a consequence, Western concepts ended up having different meanings in the Japanese context.

Key words: Japanese cinema, national cinema, transnationality, film theory, postwar cinema

\section{El DESCUBRIMIENTO OCCIDENTAL DEL CINE JAPONÉS}

\subsection{El cine como expresión de la cultura nacional}

Tradicionalmente, la literatura sobre el cine japonés ha buscado justificar la existencia de un «cine nacional» construido sobre un universo autorreferencial, dominado por convenciones narrativas y estéticas singulares y propias. Desde que el visionario Siegfried Kracauer propusiera el cine como la expresión cultural de una nación, ${ }^{2}$ la filmografía japonesa ha servido a menudo como ejemplo paradigmático de este planteamiento. Poco después, George Sadoul en Histoire du cinéma mondial daría un nuevo impulso a esta corriente señalando cómo la nación y el pueblo en su diversidad sería el material en el que se fundamenta gran número de obras fílmicas. ${ }^{3}$

Más recientemente, una tendencia desde acercamientos semióticos e impulsada por Stephen Crofts, Philip Rosen y Stephen Prince han vinculado el cine a una cultura nacional, articulando un «culturalismo» en los estudios fílmicos descrito por David Bordwell. ${ }^{4} \mathrm{El}$ mismo Prince advierte

2 Siegfried Kracauer, From Caligari to Hitler: A Psychological History of the German Film, 1947 (tr. esp. Héctor Grossi, De Caligari a Hitler: historia psicológica del cine alemán. Barcelona, Paidós, 1985).

3 George Sadoul, Histoire du cinéma mondial, Paris, Flammarion, 1966.

4 David Bordwell y Noël Carroll, eds., Post-theory: Reconstructing Film Studies. Madison, University of Wisconsin Press, 1996: 1-4. 
sobre la necesidad de estudiar dónde y dónde no las variables culturales producen significado en la imagen cinematográfica. Mantiene que en el discurso, lingüístico o cinematográfico, el signo está culturalmente establecido, lo que le lleva a la conclusión que el sistema de signos no produce significado fuera del contexto social y cultural. ${ }^{5}$ Por su parte, Crofts define el cine nacional por oposición al cine de Hollywood, es decir, aún a riesgo de caer en una tautología, el verdadero cine nacional sería sólo aquel que resiste o ignora el modelo de representación institucional. ${ }^{6}$

Por último, Rosen toma la noción de intertextualidad de Kristeva para delimitar el «cine nacional» como un grupo coherente de films que producen un supuesto conocimiento de la cultural nacional. 7 Para ello es necesario que haya cierta solidez en la producción fílmica, es decir que tenga suficiente peso histórico como para poder producir un macrodiscurso cinematográfico propio. La existencia del «cine nacional» depende de la coherencia de un imaginario común y un universo referencial propio.

No obstante, estos planteamientos presentan una limitación básica, sólo abordan las obras cinematográficas desde dentro de las fronteras nacionales e ignora fenómenos transnacionales de diversa índole que se pueden encontrar en producción, distribución, consumo de los films. Prince obvio que la fuente de inspiración de los autores se puede encontrar más allá del contexto cultural del lugar geográfico donde se realizó el film. Crofts ignora el hecho que films de referencia de los cines nacionales no necesariamente ignoran el modo de representación institucional. Asimismo, las diferencias entre cine de autor vinculado a la alta cultura y el cine comercial asociado a la cultura popular son a menudo difusas. ${ }^{8}$ Asimismo, Prince y Crofts no abordan el hecho que el cine pueden no ser

5 Stephen Prince, Explorations in Film Theory: Selected Essays from Cine-Tracs, Bloomington, Indiana University Press, 1991: XV. Para más información sobre su modelo lingüístico de inspiración saussuriana, aplicado al estudio de la imagen, vid. S. Prince, «The Discourse of Pictures: Iconicity and Film Studies», Film Quarterly, 47/1 (1993): 16-28.

6 Stephen Crofts, «Reconceptualizing National Cinema/s», Quarterly Review of Film and Video, 14/3 (1993): 49-67.

7 Philip Rosen, «History, Textuality, Nation: Kracauer, Burch and Some Problems in the Study of National Cinemas», Iris 2/2 (1984): 17-28.

8 Bourdieu, ya advirtió que las fronteras entre la alta cultura y la cultura popular son en realidad difusas, en Pierre Bourdieu, «The Field of Cultural Production, or: The Economic World Reversed», en The Field of Cultural Production, New York, Columbia University Press, 1993: 29-74. 
necesariamente expresión cultural de una tradición estética milenaria, de hecho, gran numero de films sólo pueden explicarse poniendo en cuestión, es decir, como reacción a la tradición cultural del lugar de producción. Por último, Rosen reduce el imaginario del «cine nacional» exclusivamente a referentes locales, una visión empobrecida que no tiene en cuenta una intertextualidad más amplia, sin ignorar la complicidad fuera de las fronteras nacionales. Higson ya puso en cuestión los límites de esta concepción «nacional» del cine y sentando las bases para acercamientos transnacionales, como propuesto por Hjort, categorizando distintas formas de entender lo transnacional en los estudios fílmicos. ${ }^{9}$

\subsection{La especificidad japonesa}

E ste debate es especialmente relevante en el caso del cine japonés. El autor que más rotundamente defendido la especificidad de este «cine nacional» fue Noël Burch. En su conocido To the Distant Observer, explicó como este cine es una práctica cultural inherente a una tradición que le hacía desafiar los patrones occidentales de reprsentación. ${ }^{10}$ Burch adopta un "giro a Oriente» en el que se trataba de ver desarrollos estéticos y filosóficos antitéticos a aquellos planteados en Occidente, que luego apoyarán David Bordwell y Kristin Thompson. ${ }^{11}$

En su momento, estas contribuciones acentuaron el valor del cine japonés frente a aquellos autores que lamentaban el aparente retraso de esta cinematografía en adaptar los códigos narrativos occidentales, tratando de entender sus películas en relación a lo que aportaban al modelo occidental. Cuando Burch advirtió que este cine no tenía por qué seguir los cánones occidentales, sino que de hecho parecía evolucionar a partir de sus propios referentes culturales, se entró en la paradoja de describir el clasicismo de Yasujirō Ozu o Kenji Mizoguchi como moderno, en la medida que no se amoldaba a la evolución estética y narrativa occidental.

9 Andrew Higson, «The Concept of National Cinema», Screen 30/4 (1989): 36-46; Mette Hjort, «Chapter 2. On the Plurality of Cinematic Transnationalism», en K. Newman \& N. Durovicova eds., World Cinemas, Transnational Perspectives. London: Routledge/ American Film Institute Reader, 2009: 12-31.

10 Noël Burch, "A Rule and its Ubiquity» en To the distant observer: form and meaning in the Japanese cinema, Berkeley, University of California Press, 1979: 67-74.

11 David Bordwell y Kristin Thomson, «Space and Narrative in the Films of Ozu», Screen 17/2 (1976): 41-73; También vid. David Bordwell, Ozu adn the Poetics of Cinema. Princeton, Princeton University Press, 1988. 
Sin embargo, con las contribuciones de Burch, y otros que desde una perspectiva más amplia de los estudios culturales, como Roland Barthe ${ }^{12}$ trataron de desafiar el eurocentrismo en la interpretación cultural, los acercamientos contemporáneos debería ser capaces de superar ese primer fenómeno de extrañamiento experimentado por el «observador distante» y matizar la especificidad de los códigos cinematográficos sin ignorar las interacciones entre lo local y lo global. «Influencia occidental» y «especificidad» no tienen por qué ser necesariamente excluyentes y ponerlos en diálogo es imprescindible para evaluar en profundidad la naturaleza de los films japoneses. De hecho, aunque lo dejó sin desarrollar, el mismo Burch ya abría la posibilidad de estudiar la especificidad japonesa a partir de una singular adaptación de códigos occidentales:

There is an awkward problem which the observer of things Japanese must confront. It is one to which we have already alluded in its ideological formulation: the uniquely Japanese faculty for assimilating and transforming elements 'borrowed' from foreign cultures. To my knowledge, no substantial effort has yet been made in the West to define or analyse this phenomenon, though it has often been commented upon. ${ }^{13}$

Gradualmente se ha ido entendiendo que cualquier interpretación esencialista del cine nacional en última instancia tiende a fracasar. Thomas Elsaesser ya había señalado la existencia de fenómenos internacionales en la construcción del cine nacional en el caso alemán. ${ }^{14}$ Para Elsaesser, el Nuevo Cine Alemán parecía ser más coherente fuera que dentro de Alemania, donde sólo alcanzaba un $8 \%$ de audiencia. El público extranjero recibía bien aspectos de su historia nacional (nazismo, temas bélicos, la sofisticada escenografía, etc.) mientras las audiencias locales preferían films de conciencia social (feminismo, regionalismo o temas de minorías oprimidas) que en otros países se desviaban a los reportajes televisivos.

Este estudio es especialmente relevante porque pone de relieve cómo a menudo el cine nacional acaba por construirse desde fuera. En Japón, se ha advertido en varias ocasiones que la constitución de la visión nacional de su cine surge en gran medida de los autores extranjeros. Kikuo Yamamoto

12 Roland Barthes, L'Émpire des signes, París, Flammarion, 1984.

13 Noël Burch, «Transformational Modules» en To the Distant Observer... 1979: 89-92.

14 Thomas Elsaesser, New German Cinema: A History, Hampshire, British Film Institute, 1989. 
señaló que fue Donald Richie el primero en llamar a Ozu «el más japonés» de los directores. ${ }^{15}$ Por su parte, Akira Kurosawa se convirtió en representante de la japonesidad cinematográfica tras el éxito de su película Rashomon en Europa a principios de los cincuenta, periodo en el que precisamente fue descubierto el cine japonés en Occidente.

\subsection{La construcción occidental del cine nacional japonés}

El cine japonés había tenido algunos contactos con el público occidental desde épocas muy tempranas: Eisenstein afirmaba haber visto una exhibición en Moscú en los años veinte; Teinosuke Kinugasa viajó hasta Berlín para presentar Jüjiro (1928), película que de allí se distribuyó por otros lugares de Europa. ${ }^{16}$ De hecho, hay constancia de la proyección de Jüjiro junto con otras películas japonesas en París en el periodo de entreguerras, que incluso generó alguna reseña en España, como ha señalado David Almazán. ${ }^{17}$ Sin embargo, esto no fueron más que hechos anecdóticos y aunque la japonesa ha sido una de las industrias cinematográficas más antiguas y prolíficas del mundo - en los años veinte ya estrenaba más de 300 películas anuales-, esta producción fue desconocida en Occidente hasta el descubrimiento occidental del cine japonés en los años cincuenta, con la oleada de películas japonesas que arrasó en los principales festivales europeos: Akira Kurosawa obtuvo con Rashomon el León de Oro del festival de Venecia y un Oscar en 1951; además sus protagonistas, Toshiro Mifune y Machiko Kyo, se convertirán en actores de prestigio internacional. Ese año Historia de Genji (Genji monogatari) de Kōzaburō Yoshimura es nominada en Cannes y gana el gran premio de fotografía en Venecia. El año

15 Kikuo Yamamoto, Nihon eiga ni okeru gaikoku eiga no eikyo (La influencia del cine extranjero en el cine japonés)「日本映画における外国映画の影響」, Tokyo, Waseda Daigaku Shuppanbu, 1983: 629.

16 Fue distribuida por Francia, Inglaterra y también en Nueva York con el título Shadows of Yoshiwara. Según Max Tessier, Kinugasa fue entrevistado por Roger Régent para Pour Vous en 1929. Vid. Max Tessier, Images du cinéma japonais, Paris, Henry Veyrier, 1981: 28.

17 David Almazán cita el artículo de Román Marvá «La moderna cinematografía japonesa», publicado en Blanco y Negro, 28-4-1929. Además Almazán habla de una tendencia del cine occidental, entre los años veinte y principios de los treinta, a ambientar películas en el Lejano Oriente, con actores especializados en personajes orientales (como Lon Chaney o el español Ernesto Vilches) o incluso con reconocidos actores japoneses (como Sessue Hayakawa, Tsuru Aoki, Kamoka Sunada o Yoshiko Okada). David Almazán, "Antes de Kurosawa: primeras noticias sobre el cine japonés en España», Studium: Revista de Humanidades, 7 (2000): 10. 
siguiente se inicia el descubrimiento de otro de los primeros maestros, Kenji Mizoguchi que se llevó el León de Oro por Vida de Oharu (Saikaku ichidai onna), en 1953 el León de Plata por Los cuentos de la luna pálida de agosto (Ugetsu monogatari) y en $1954 \mathrm{el} \mathrm{mismo} \mathrm{premio} \mathrm{por} \mathrm{El} \mathrm{intendente}$ Sansho (Sanshō dayū).

En 1954, Kurosawa vuelve a Venecia donde consigue el León de Plata por Los siete samuráis (Shichinin no samurai), que además obtuvo dos nominaciones a los Oscar y Teinosuke Kinugasa gana la Palma de Oro y dos Oscars por La puerta del infierno (Jigokumon). Daiei vuelve a intentarlo los años siguientes con otras películas de Mizoguchi: la adaptación de la obra de teatro kabuki del siglo XVII, Los amantes crucificados (Chikamatsu monogatari), nominada mejor película en Cannes en 1955; La emperatriz Yang Kwei-fei (Yokihi), una historia de amor ambientada en el siglo VIII que fue nominada a mejor película en Venecia el mismo año, al igual que La calle de la vergüenza (Akasen chitai) en 1956. Nikkatsu hace lo propio en 1958 con The Temptress and the Monk (Byakuya no Yōjo) de Eisuke Takizawa, la historia de un monje budista y una bruja que será nominada en Berlín. Ese año en Berlín, Tadashi Imai recibirá el Oso de Plata por The Story of Pure Love (Junai monogatari) y en Hiroshi Inagaki consigue el León de Oro por El hombre del carrito (Muhomatsu no issho), donde Toshiro Mifune es un pobre conductor de carro en el periodo Meiji.

Los años cincuenta también marcan el descubrimiento del cine japonés por parte del público estadounidense. Además de las oscarizadas Rashomon y La puerta del infierno, las referencias a películas japonesas a partir de 1952 muestran el nuevo interés por este cine en Estados Unidos. ${ }^{18}$ En el anuario americano Variety's Film Review encontramos reseñas a La bella $y$ los ladrones (Bijo to Tōzoku, Keigo Kimura, 1952), donde Daiei intenta capitalizar el éxito de Rashomon con la versión de un clásico de teatro Kabuki, ambientada en el Japón del siglo XI o Adventure of Natsuko (Natsuko no bōken, Noboru Nakamura, 1953), una adaptación de la novela de Yukio Mishima. ${ }^{19}$ Además aparecen películas que intentan atraer al público norteamericano abordando cuestiones bilaterales como Forever My Love (Itsu itsu made mo, Paul Sloane, 1952), sobre un sargento americano que se enamora de una japonesa; ${ }^{20}$ Confusion (Yassa mossa, Kinoru Shibu-

18 Cfr. Variety's Film Review, R. Bowkers, New York, 1949-1959.

19 Cfr. Variety's Film Review, R. Bowkers, New York, 22-10-1952.

20 Producida por Daiei pero dirigida por el Paul H. Sloane y protagonizada por Chris Drake, y Mitsuko Kimura en el papel femenino. El film es uno de los ejemplos de Daiei por 
ya, 1953) sobre los niños de padres americanos en la posguerra; General Yamashita (Tomoyuki Yamashita, Hiroshi Okawa, 1953) sobre la guerra en Filipinas o Hiroshima (de Hideo Sekigawa, 1955) sobre los efectos de la bomba, que incluye material de archivo y algunas secuencias narradas en inglés. Otra película ambientada en el pasado legendario, Samurai (Hiroshi Inagaki, 1954) ambientada en el s. XVII, obtendrá el Oscar a la mejor película de habla no inglesa en $1955 .{ }^{21}$

\subsection{El «efecto kimono»}

Tras un breve repaso por las películas que marcaron la irrupción de películas japonesas en Occidente uno puede darse cuenta que tienen algo en común: todas ellas son películas de época (jidaigeki). Los films que habían triunfado en Europa y Estados Unidos presentaban un Japón legendario anclado en su cultura tradicional. Sin embargo, en 1956 Shinobu y Marcel Giuglaris señalan un hecho paradójico: inicialmente estas películas no habían tenido ningún éxito en Japón. Rashomon fue considerada por la crítica japonesa como un film «ampuloso, incomprensible y falso». Ni siquiera fue considerada una película de clase B ni se recomendó en las escuelas. ${ }^{22}$ Meses más tarde, tras ganar el León de Oro en Venecia, fue de nuevo estrenada en Japón. Los Giuglaris relatan en primera persona el estupor y la decepción causada en los espectadores a la salida: «Realmente no entendemos nada [...] No es posible que esta película haya sido premiada por un jurado extranjero». ${ }^{23}$ Lo mismo ocurrió con La puerta del Infierno, una película que ni siquiera había sido incluida dentro de las 10 mejores pelícu-

dirigirse al mercado internacional. En 1953, como parte de la estrategia de llegar al mercado estadounidense, el director americano Josef von Sternberg dirige otra producción japonesa La saga de Anatahan (Ana-ta-han, 1953), estrenada en el Plaza Theatre de Nueva York el 17 de mayo de 1953.

21 La moda por el exotismo japonés parece dejar paso a final de la década a películas de los llamados Humanistas de Posguerra. En Estados Unidos se estrenan: La condición bumana (Ningen no joken, 1959) de Masaki Kobayashi, Nueva York, 30 de diciembre, 1959, Carmen vuelve a casa (Karumen kokyō ni kaeru, 1951) de Kinoshita Keishuke, en Nueva York el 28 de diciembre. En Europa también se abren paso estos directores: La llave (Kagi) de Kon Ichikawa obtiene el premio del jurado en el festival de Cannes y el Globo de Oro a la mejor película de habla no inglesa en 1959; ese año también se estrenan en Venecia, aunque sin premio, Conflagración (Enjo) de Ichikawa y Kiku and Isamu (Kiku to Isamu) de Tadashi Imai.

22 Shinobu Giuglaris y Marcel Giuglaris, Le cinema japonais. Paris, du Cerf, 1956 (edición española El cine japonés. Madrid, Rialp, 1957: 27).

23 Ibidem. 


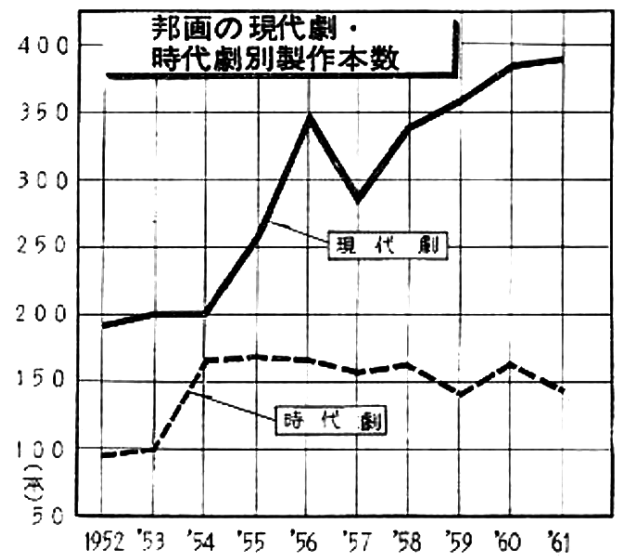

(1) 54年各.5束决方i 2 本立䦿給知盟始。

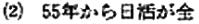

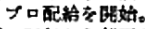

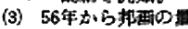

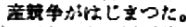
(4) 58年方ら日活が時

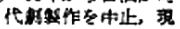

代其一本にした。

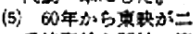

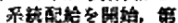

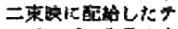
レビ・ブロ作确8本 b含击九ている。

(6) 61年忙6月加可布

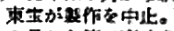

5 召から第二事踙を

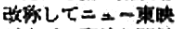

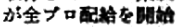
したが12月から東肤 乐化一本化し, 二=

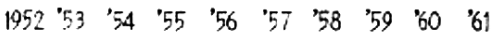

一柬眏籍此した。

Gráfico 1. Producción de gendaigeki, dramas contemporáneos (línea continua), y jidaigeki, películas de época (línea discontinua), entre 1952 y 1961. Extraído de Eiga nenkan, Tokio, Jiji tsūshinsha, 1963: 36.

las del año. De hecho, fue un estrepitoso fracaso de taquilla, pero cuatro meses más tarde se llevaba en Cannes la Palma de Oro.

¿Por qué razón estas películas que no llamaban la atención en Japón eran tan exitosas en Occidente? En realidad, mientras en Europa las películas ambientadas en el pasado feudal eran extremadamente atractivas, en Japón distaban mucho de ser el género de moda. Como vemos en la gráfica publicada en el Eiga nenkan [Anuario cinematográfico], en la década de los cincuenta, la producción jidaigeki, estaba muy por debajo de los «dramas contemporáneos» (gendaigeki). De hecho, el interés por las películas ambientadas en la época contemporánea se dispara a partir de 1954, justo en el momento en que el cine histórico entra en lento y prolongado retroceso y los estudios Nikkatsu llega a cesar su producción de jidaigeki en 1958 (nota 4 del Gráfico 1).

A diferencia de la audiencia nipona, lo exótico de estos films resultaba excitante para el espectador occidental. David Bordwell también se percató de lo ya sostenido por Shinoba y Marcel Giuglaris: era de un exotismo tan elevado que ni los japoneses se reconocían en él. ${ }^{24}$ Sin embargo, esto no

24 David Bordwell, Film history: an Introduction. New York, McGraw Hill, 1994. 
fue un hecho casual, sino que se trataba de una política deliberada de los estudios, orientada a asombrar al público extranjero con imágenes de un Japón anclado en la tradición. De esta manera se potenció en Europa lo que Antonio Weinrichter ha llamado el «efecto kimono», esto es, el asombro del público occidental ante el exotismo de las películas japonesas. ${ }^{25}$ Por tanto, no se puede decir que estas las muestras proyectadas en los festivales europeos respondieran a los gustos generales del público japonés. Los films distribuidos en Europa y Estados Unidos provenían principalmente de producciones rodadas por Daiei en los estudios de Kyoto, orientadas al mercado internacional, como reconoció el mismo presidente de los estudios, Masaichi Nagata:

La solución ideal para el cine japonés era conquistar el mercado americano. Pero eso parecía difícil. La experiencia demostraba que los films europeos no se habían impuesto nunca en el mercado norteamericano. Y esto merecía ser tenido en cuenta. Se procedió entonces a un estudio concienzudo de los mercados internacionales y se advirtió que el punto débil lo constituían los países europeos. Fue entonces cuando se decidió lanzar films típicos, históricos, exóticos y culturales para presentarlos en los festivales, especialmente Venecia y Cannes. ${ }^{26}$

Este hecho problematiza de manera significativa la concepción nacional con las que se articuló durante años se tuvo del caso japonés. Asombrados por la extrañeza formal de sus películas, muchos autores se vieron impulsados a subrayar los rasgos de estilo que más separaban el cine nipón de la norma occidental. Pero los autores partían de una visión fragmentada de esta filmografía, basada en un corpus preseleccionado que acentuaba los rasgos que la vinculan este cine a su cultura tradicional. Eran películas destinadas en gran medida a ser exportadas lo cual hace que la construcción teórica del cine nacional fuera altamente contradictoria e ignoraba la complejidad de las interacciones entre los local y lo global. Los trabajos más sobresalientes de Kurosawa están inspirados por la filosofía y conflictos morales retratados en la literatura occidental: adaptó el «Rey Lear» de William Shakespeare en Ran (1985), «Macbeth» en Trono de sangre (1957), «La muerte de Ivan Ilich de Leo Tolstoi le sirvió de inspiración para Vivir

25 Antonio Weinrichter, Pantalla amarilla: el cine japonés. Las Palmas de Gran Canaria, Festival Internacional de Cine, 2002.

26 Giuglaris y Giuglaris, 1957: 32. Cabe destacar que la mayor parte de las películas premiadas en festivales europeos eran producidas por Daiei. A diferencia de los otros cinco grandes estudios de los años cincuenta (Shōchiku, Tōhō, Shintōhō, Toei y Nikkatsu), no tenían apenas red de distribución y poseía pocas salas de exhibición, por lo que se vieron obligados a seguir una política orientada a la exportación extranjera. 
(Ikiru, 1952) y Los siete samuráis (Shichinin no samurái, 1954) es una referencia a la obra griega «Los siete contra Tebas» de Esquilo.

Asimismo, Mizoguchi se convirtió en el principal representante del clasicismo cinematográfico japonés junto con Yasujirō Ozu, que fue reconocido en Occidente una década después de su muerte y de quien Donald Richie dijo que se trataba de el más japonés de los directores japoneses. ${ }^{27}$ Sin embargo, no se debe pasar por alto que irónicamente Ozu y Mizoguchi pertenecieron en el inicio de sus carreras a un grupo de cineastas que buscaban modernizar el cine de los años veinte adaptando modelos occidentales. Por ejemplo, ambos se opusieron a la tradición Kabuki del onnagata, hombres interpretando papeles femeninos, y rechazaron el espectáculo cinematográfico dominado por los benshi, quienes narraban e interpretaban los films libremente introduciendo intertítulos entre las escenas de sus películas mudas para fijar el sentido de la acción y evitar la presencia de estos narradores. Además, la irrupción de películas extranjeras de Fritz Lang, Friedrich Munrau, Ernst Lubitsch, Howard Hawks, Josef von Sternberg o Erich von Stroheim para cubrir la falta de nuevos estrenos tras gran terremoto de Kanto de 1923 tuvo un gran impacto sobre ellos.

\section{LA Deconstrucción DE LA «Visión NAcional»}

\subsection{El mito del hermetismo japonés}

La literatura sobre el cine japonés suele afirmar que esta filmografía consiguió desarrollar sus propios códigos narrativos y estéticos alejados de los occidentales. Burch encuentra las razones de esta especificidad en el contexto histórico: en dos mil años, ninguna parte de Japón ha sido ocupada, hasta la derrota de $1945 .{ }^{28}$ El país nunca tuvo un estatus semicolonial como China o una dependencia total como la India. Por ello, aunque estos países también desarrollaron una prolífica industria cinematográfica, no pudieron desarrollar medios de representación completamente originales (autóctonos). Al igual que Burch, Nygren, sostiene que la originalidad japonesa fue posible gracias a una autonomía técnica y económica de su

27 Donald Richie, Ozu: His Life and Films. Berkeley, University of California Press, 1974.

28 Burch, 1979: 27. 
industria cinematográfica. ${ }^{29}$ En efecto, la producción japonesa comenzó en una edad muy temprana, con la llegada del cinematógrafo de los Lumière, varias tiendas de fotografía se hicieron con cámaras y sus operadores (Asano Shiro para la empresa Konishi; Shibata Tsunekichi y Shirai Kanzo para los almacenes Mitsukoshi) comenzaron a rodar sus propios films ${ }^{30}$ Japón formaba a sus propios técnicos y revelaba las películas en sus propios laboratorios. En definitiva, la autosuficiencia de su infraestructura habría hecho posible la interacción del cinematógrafo con su cultura milenaria. Pero frente a este argumento cabe preguntarse dos cuestiones: Primero, ¿sólo la autonomía funcional de la industria fílmica japonesa bastaba para crear un cine esencialmente nacional? Segundo, ¿ este hecho garantizaba la ausencia de influencias estéticas extranjeras?

\subsection{La influencia extranjera}

Recientemente algunos han cuestionado este supuesto hermetismo de la producción cinematográfica nipona. Autores como Gregory Barrett, Donald Kirihara, David Desser, Michael Raine, Mitsuhiro Yoshimoto o Aaron Gerow, han puesto en evidencia que la independencia cinematográfica de este país es más compleja de lo que se pensaba. La producción cultural parece haber sido inevitablemente atravesada por corrientes venidas de fuera, desde antiguo. El mismo Eisenstein, que fue uno de los primeros defensores de la especificidad japonesa, había señalado ya en los años veinte que esta industria tampoco escapaba a fenómenos internacionales. En una exhibición de cine japonés realizada en Moscú el año 1929, afirmaba que al igual que el cine europeo y americano, el japonés había entrado en la carrera comercial. La misma idea es desarrollada en Japón por otro autor marxista, Akira Iwasaki en Eiga to Sibon shugi [Cine y capitalismo] (1931). ${ }^{31}$

Debemos tener en cuenta que en realidad, el cine era un artefacto internacional antes que ser nacional. La imagen fotomecánica (eizō) fue considerada en Japón fruto de un mecanismo extranjero, que reproducía códi-

29 Scott Nygren, Time Frames. Japanese Cinema and the Unfolding of History. Minneapolis, London, University of Minnesota Press, 2007.

30 Michiko Usui habla de las primeras películas rodadas por un japonés, Inazuma goto Hobaku no ba (1899) y Momijigari (1899) de Shibata Tsunekichi, en «The Roots of Japanese Movies as Seen in the Tsubouchi Memorial Theatre Museum Collection", Yomiuri Shinbun. Ver en: http://www.yomiuri.co.jp/adv/wol/dy/ culture/080717.htm

31 Akira Iwasaki, Eiga to shihon shugi 「映画と資本主義」( (Cine y capitalismo»), Tokio, Ōraisha, 1931. 


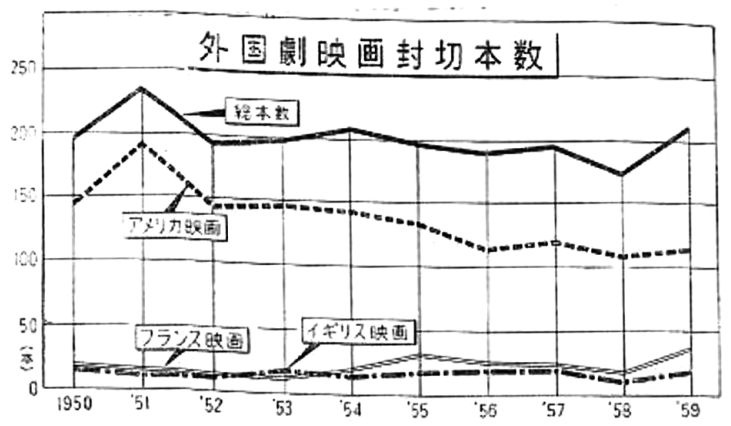

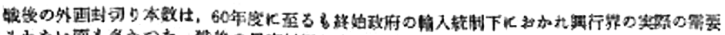

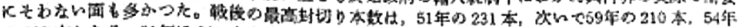

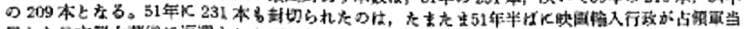

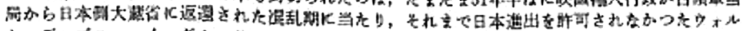

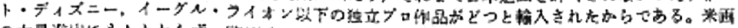

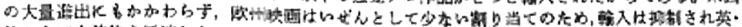

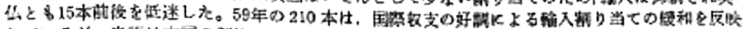

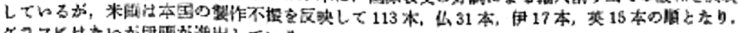
タフフKはないが卧が治出している。
\end{abstract}

Gráfico 2. Número de películas estrenadas en Japón entre 1950 y 1959. De producción nacional (línea negra), americanas (punteada), francesas (línea gris) e italianas (rayas y puntos).

Eiga nenkan「映画年鑑」, Tokio, Jiji tsūshinsha, 1961, p.43

gos y modos de representación occidentales, considerados ajenos a las prácticas artísticas tradicionales. Por ejemplo, el escritor Junichirō Tanizaki impregnado por el espíritu de «restauración» $(f u k k \bar{o})$, o vuelta al Japón tradicional, como reacción a la occidentalización de la era Taishō (19121926), escribe su célebre El elogio de la sombra (Inei raisan, 1933), en el que afirma que el cine había obligado a abandonar la tradición japonesa, en favor de una concepción occidental en el uso de la luz y la sombra. Mientras en Occidente, el arte está basado en la luz y lo oscuro tenía connotaciones negativas, en Japón la sombra siempre había sido parte de la belleza del arte (concebida como un espacio de coexistencia de luces y sombras). Sin embargo, la adopción de tecnología occidental parecía obligar a Japón a abandonar sus costumbres estéticas milenarias. ${ }^{32}$

En este sentido, debemos subrayar lo problemático que resulta considerar el cine japonés totalmente ajeno a las prácticas extranjera. Los directores

32 Junichirō Tanizaki, «Inei raisan»「陰鸨礼讃」 en Keizai ōrai, Tokio, Nihon hyōronsha, 12-1933 / 01-1934 (El elogio de la sombra, Madrid, Siruela, 1994). 
así como los espectadores nunca estuvieron aislados del resto del mundo. En realidad, gran parte de lo que se veía en las salas de cine japonesas eran películas extranjeras, sobre todo de Hollywood pero también de Europa y posteriormente de otros países asiáticos. ${ }^{33}$ La gráfica inferior muestra que en la década del descubrimiento y construcción occidental del cine japonés como «cine nacional», años cincuenta, el número de producciones extranjeras estrenadas no era una cuestión menor. ${ }^{34}$

\subsection{Visión «postnacional»}

Nuestro argumento no trata de negar las influencias de la tradición filosofía, estética y artística japonesa en el cine. Pero debemos matizar que los autores occidentales han pasado por alto con demasiada frecuencia la sensibilidad de los creadores japoneses a las ideas y prácticas extranjeras. Como consecuencia, Japón también puede y debe ser estudiado como un excepcional lugar de tránsito internacional de imágenes, sin que por ello los autores y sus obras pierdan autenticidad. Gerow señala cómo el cine forma parte de una tradición cultural del siglo XX abarrotada de múltiples referencias extranjeras. ${ }^{35}$ En este sentido, David Desser habla de la nueva ola japonesa como parte de un movimiento que se extiende más allá de sus fronteras nacionales. ${ }^{36}$ Gregory Barrett da cuenta no sólo de unos arquetipos que se remontan al folclore, la mitología o la literatura, sino también de otros surgidos del conflicto entre tradición y modernización, así como de la relación dialéctica con Occidente. ${ }^{37}$ Bajo esta concepción que podemos denominar «postnacional» del cine, Donald Kirihara aborda el problema de la especificidad japonesa, advirtiendo del peligro de caer en el

33 Dudley Andrew y Michael Raine, «Japanese Image Culture», Iris. Image Theory, Image Culture, and Contemporary Japan, 16 (1993): 3-9.

34 En la evolución de la exhibición de películas en los años cincuenta, vemos que el cine extranjero ocupaba entre el 25 y el $50 \%$ del cine japonés. Vid. Tabla del anuario Eiga nenkan「映画年鑑」, Tokio, Jiji tsūshinsha, 1963: 35. Sobre la exhibición de las películas de Hollywood en Japón y la influencia en su cultura popular, vid. Kitamura Hiroshi, «The Exhibition of American Movies» y «The Culture Elites and American Movies» en Screening Enlightenment. Hollywood and the Cultural Reconstruction of Defeated Japan, Ithaca, Cornell University Press, 2010: 112-155.

35 Aaron Gerow, «Celluloid Masks: The Cinematic image and the Image of Japan», Iris, 16 (1993): 23-36.

36 David Desser, Eros Plus Massacre: An Introduction to The Japanese New Wave Cinema, Bloomington, Indiana University Press, 1988: 15.

37 Gregory Barrett, Archetypes in Japanese Film. The Sociopolitical and Religious Significance of the Principal Heroes and Heroines, London, Associated University Press, 1989. 
«orientalismo esencialista» de algunos teóricos del cine nacional ${ }^{38}$ Frente a los que encuentran en el clasicismo cinematográfico el máximo exponente de la japonesidad, Kirihara plantea que lejos de volver a las tradiciones, ese cine fue lugar de una extraordinaria y rica internacionalización, como hemos señalado más arriba en el caso de Ozu y Mizoguchi. Haciendo una relectura de Burch, Kirihara plantea ¿qué es lo que hace a los films japoneses, japoneses? Su respuesta es en gran medida, la mirada de los autores occidentales. ${ }^{39}$

A la luz de estos hechos, sería conveniente reformular el cine nacional dentro de la cultura global de las imágenes que fluyen desde, hasta y a través de Japón. No desestimando el papel de la tradición japonesa sino reconociéndola y contextualizándola en medio de una amalgama de conceptos y prácticas, que se remontan tanto a tiempos remotos de la tradición japonesa (como han señalado Keiji Asanuma, Kenji Iwamoto) ${ }^{40}$ como a lugares lejanos en Occidente (de acuerdo con Michael Raine, Mitsuhiro Yoshimoto). ${ }^{41}$

\subsection{El problema de la teoría cinematográfica nacional}

El eurocentrismo en los estudios del cine ha ido privilegiando un monopolio teórico que ha eclipsado puntos de vista surgidos de lugares con tradiciones filosóficas y estéticas distintas. Creer que los autores japoneses fueron ajenos a influencias extranjeras es producto de un acercamiento superficial al problema. Dicho esto, no podemos obviar la existencia de un contexto cultural propio. Como han reivindicado algunos autores, es necesario incorporar ideas y pensamientos producidos localmente (Wimal

38 Donald Kirihara, Patterns of Time: Mizoguchi and the 1930s, Madison, University of Wisconsin Press, 1992.

39 Donald Kirihara, «Reconstructing Japanese Film», en David Bordwell y Noël Carroll, eds., Post-Theory: Reconstructing Film Studies. University of Wisconsin Press, 1996: 501-519; Aaron Gerow, «Introduction: The Theory Complex», Review of Japanese Culture and Society. [Descentering Theory: Reconsidering the History of Japanese Film Theory], 22 (2010): 1-14.

40 Kenji Iwamoto, «Japanese Cinema Until 1930: A Consideration of its Formal Aspects», Iris, 16 (1993): 9-23; Keiji Asanuma, «The Theory of Cinema and Traditional Aesthetic Thought of Japan», Iris, 16 (1993): 127-145.

41 Mitsuhiro Yoshimoto explica cómo Japón se ha convertido en un ejemplo de postmodernidad a partir de retóricas internacionales, tomando como ejemplo el caso de Tokyo Disneyland, en «Le postmoderne et les images de masse au Japon» en Iris, 16 (1993): 9-23. 


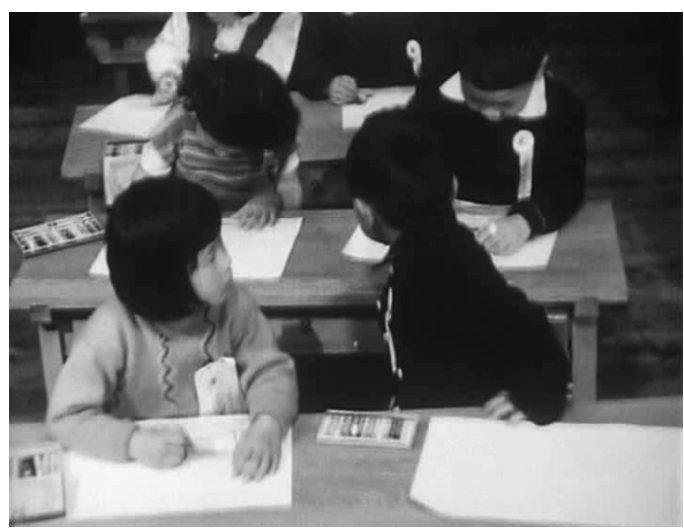

La contemplación del instante. Children Who Draw.

Dissanayake, Keiji Asanuma, Tadao Satō, Kenji Iwamoto). ${ }^{42}$ Si la teoría cinematográfica aspira a ser global, necesitaría revestirse de conceptos que hasta ahora le han sido extraños. Pese a las abundantes influencias extranjeras, los films japoneses a menudo poseen unas singularidades que remiten a un trasfondo cultural filosófico-religioso que no se debe pasar por alto.

Muchos autores han afirmado que para rastrear conceptos estéticos no contaminados, habría que remontarse a periodos anteriores a la modernización Meiji (Burch, Barthes, Bordwell, Asanuma, Iwamoto). El Mono no aware, el pathos de las cosas, la contemplación de lo efímero se ha utilizado a menudo para el análisis del cine japonés, especialmente para el caso de Ozu. Sin embargo, en el cine modernista de Hani, existe una intención de filmar acciones espontáneas e imprevisibles de los personajes, capturar el instante irrepetible que parece remitir a una conciencia del carácter efímero de las cosas, propia del haiku y el tanka. Como consecuencia las obras cinematográficas de Hani tienen en este sentido una condición fugaz y pasajera que tenía Ozu pero también el poeta Matsuo Basho. Sin embargo,

42 Wimal Dissanayake y Rob Wilson, eds., Global/Local: Cultural Production and the Transnational Imaginary, Durham, Duke University Press, 1996. Cfr. Wimal Dissanayake, «Narrative, Spectacle and Disruption: The Discourse of the Body in Takeshi Kitano’s Zatōichi» en el congreso coordinado por Andreas Becker y Kayo Adachi-Rabe, Shintai/soma, Frankfurt, Goethe-Universität, 25-07-2013. 


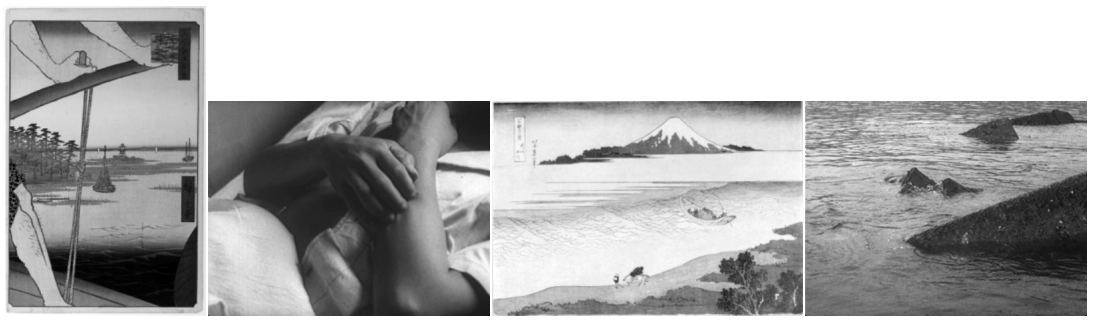

La representación del kire.

Ukiyo-e El ferry de Haneda y el templo de Benten de la serie de "Cien vistas de Edo", Hiroshige (fig. 1). Escena 7, Bad Boys (fig. 2). Ukiyo-e El río Tamagawa, provincia de Musashi de la serie «37 vistas del monte Fuji», Hokusai (fig. 3). Escena 32, Bad Boys (fig. 4).

en sus documentales trascendió este concepto en la medida que no se limitó a la observación externa de las cosas, sino que intentó explorar su lógica interna.

El kire o «corte» es otro concepto estético que algunos han identificado como singular del arte tradicional japonés (Ryōsuke Ōhashi) que también se puede rastrear en el cine. Se trata de la representaciones metonímicas de una parte que aparece aislada, algo que ha sido extraído de un todo que no aparece. O bien la representación de un todo al que se le ha recortado una parte. Es posible aplicar el «corte» en la continuidad del relato, con planos «vacíos» que habían caracterizado el cine de Ozu (que Burch bautizó como pillow shots) insertados en el montaje sin una función narrativa clara, aunque en ocasiones sirvan de transición de una escena a otra.

La representación del «vacío» también se encontraba en numerosas formas de arte, desde la pintura japonesa (kaiga) y el grabado (ukiyo-e), hasta los espectáculos de teatro Nō. En el cine, los planos vacíos de Ozu mencionados se convirtieron en una de las marcas más características de su estilo, que en ocasiones se ha asociado al término $m u$ («nada»)..$^{43}$ La representación del «vacío» era una extrañeza para Burch o Barthes (que la observaron en el cine y en la cultura respectivamente), pero no era una manifestación artística voluntariamente rupturista, sino una práctica ligada a uno de los principales conceptos del budismo Zen: el «vacío», $k \bar{u}$ (Kondō

$43 M u$ («nada») es la palabra que se encuentra escrita en la lápida de Ozu, en el cementerio de Kamakura. 

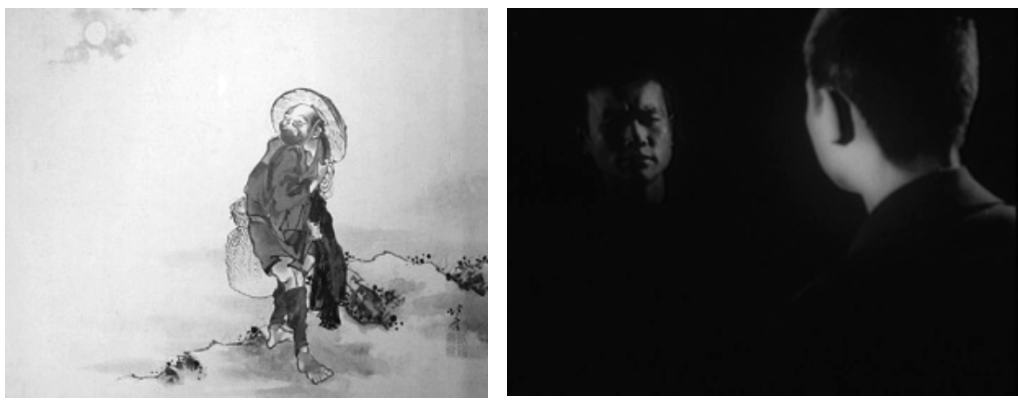

Representación del vacío en pintura japonesa (izq). Escena 40, Bad Boys (dcha).

Masaki). ${ }^{44}$ Para esta rama del budismo, el vacío era necesario para alcanzar la armonía espiritual.

A lo largo su filmografía, Hani ha ido volviendo incesantemente sobre los mismos temas: la infancia, los animales, la cultura tradicional o la juventud. Si nos centramos en los documentales de niños, observamos además cómo repite ciertos patrones, el rodaje en escuelas, el ensayo con técnicas modernas de enseñanza o el análisis de la psicología infantil. Se puede decir que la «repetición» (kurikaesu) es un rasgo característico de su cine. Pero el caso de Hani no es una excepción. Nos podemos remontar hasta Ozu, uno de los grandes maestros de la repetición, que parecía rodar una y otra vez la misma película (con los mismos actores, casi los mismos personajes y las mimas situaciones).

Sin embargo, nos referimos a un concepto de «repetición», kurisakesu, en Japón que también parece sustancialmente distinto al de Occidente. Se trata de idea que obliga a replantear el concepto de «copia», no entendida como imitación, falsedad, no-originalidad, que por tanto se asocia a una obra inferior o sin valor creativo. En las artes japonesas - desde ámbitos tan distintos como las artes marciales, el chadō (ceremonia del te) o el shodō (caligrafía japonesa) - la repetición no significa meramente imitación y pérdida de calidad, sino al contrario, se entiende como una vía de perfeccionamiento y autosuperación. En este sentido, debemos entender la repetición en el cine de Hani u Ozu como un proceso de aprendizaje y descubrimiento con el que busca continuamente nuevas y originales formas de profundizar en el interior del retratado.

44 Kondō Masaki, «The Impersonalization of the Self in an Image Society», Iris, 16 (1993): 40. 

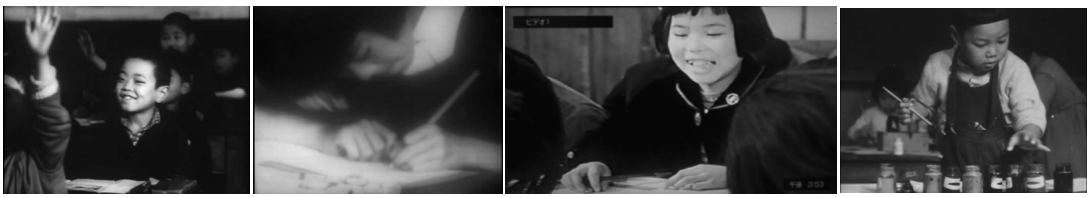

La «repetición» en la filmación de niños entre 1954 y 1956: Children in the Classroom, Estudio de gemelos, Dirección de grupos y Children Who Draw.
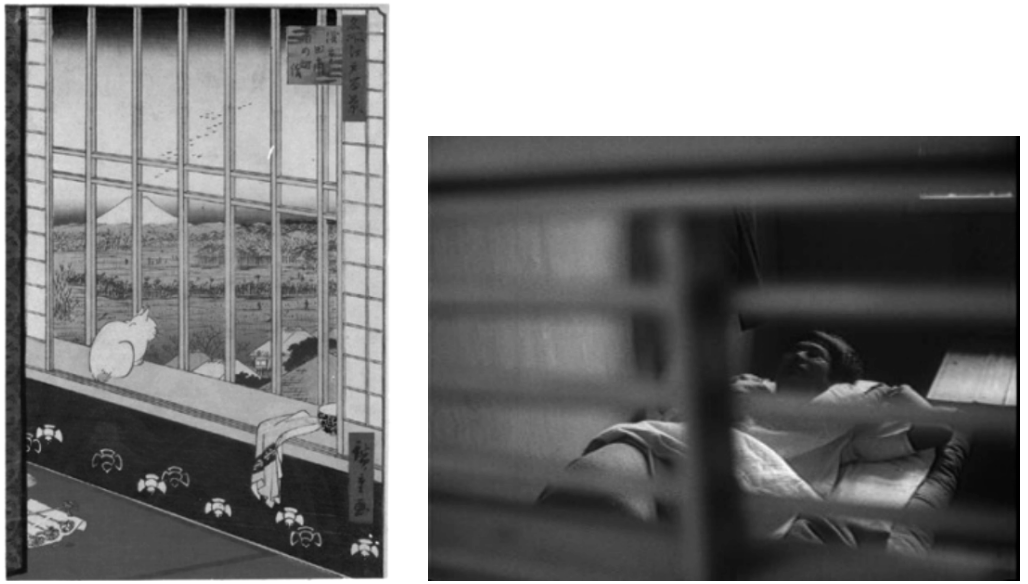

La experiencia voyeur a través de la ventana y objetos que se interponen a la mirada. Ukiyo-e Los arrozales de Asakusa y el festival de Torinomachi serie de "Cien vistas de Edo», Hiroshige (izq.). Escena 7, Bad Boys (dcha.)

En formas de expresión artísticas como el ukiyo-e, pese a su predominante representación plana, son abundantes los objetos en primer plano que se interponen entre la escena y el espectador. Del mismo modo, no son pocas las tomas de Hani en las que determinados objetos «entorpecen» la mirada, obstaculizando la forma «natural» de ver la pantalla. Pero además, las tomas a través de puertas abiertas o ventanas plantean la necesidad de un punto de vista. El recurso de filtrar o esconder la mirada detrás de un objeto evidencia la existencia de un observador, refuerza la noción de subjetividad en el plano frente a la supuesta observación «objetiva» $\mathrm{y}$ «transparente» del cine institucional. Desde el punto de vista occidental, estos recursos estilísticos parecen indicar un rasgo de la modernidad cinematográfica, pero en Japón esta vinculación es problemática pues 
no sólo aparecen en la nueva ola de Hani o Imamura, sino también en autores como Ozu e incluso, como hemos señalado, eran recurrentes en modos de representación muy anteriores del grabado japonés.

\subsection{Migración de conceptos y relativismo cultural}

Existe ya una generación de autores, Kenji Iwamoto, Abé Mark Nornes, Yuriko Furuhata o Aaron Gerow tratando de ayudar a construir un posible discurso de la teoría fílmica japonesa. ${ }^{45}$ Sin embargo, este hecho podría tener un resultado paradójico: la teoría nacional podría ayudar a describir con mucha mayor precisión la repetida «especificidad» japonesa, pero también podría servir para ponerla en cuestión. Las contribuciones de estos autores permiten poner en crisis el monopolio teórico occidental, pero también cuestionan la supuesta especificidad que tendría el marco teórico japonés.

Por un lado, ciertos autores han tratado de comprender cómo los cánones teóricos desarrollados en Occidente han penetrado en los conceptos japoneses (Andreas Becker, Kayo Adachi-Rabe) ${ }^{46}$ Pero, por otro lado, se

45 Kenji Iwamoto, «Film Criticism and the Study of Cinema in Japan: A Historical Survey», Iconics, 1 (1987): 129-146; Abe-Mark Nornes, Japanese Documentary Film: The Meiji Era through Hiroshima, Minneapolis, University of Minnesota Press, 2003; los textos de Yuriko Furuhata, "Returning to Actuality: Fūkeiron and the Landscape Film», Screen, 48/3 (2007): 345-362; Refiguring Actuality: Japan's Film Theory and Avant-Garde Documentary Movement 1950s-1960s, Ann Arbor, UMI, 2009 (tesis doctoral); y Cinema of Actuality: Japanese Avant-garde Filmmaking in the Season of Image Politics, Durham, Duke University Press, 2013; Aaron Gerow, «Introduction: The Theory Complex»y «The Process of Theory: Reading Gonda Yasunosuke and Early Film Theory», Review of Japanese Culture and Society, 22 (2010): 1-14 y 37-44.

46 Para un estudio comparativo del flujo de conceptos filosóficos y estéticos entre Europa y Japón, a través del cine, vid. Andreas Becker, Kayo Adachi-Rabe y Florian Mundhenke, eds, Japan-Europa. Wechselwirkungen zwsischen den Kulturen im Film den darstellenden Künsten (Japón-Europa. Interacciones entre la cultura del cine y las artes escénicas), Darmstadt, Büchner, 2010. Sobre la asimilación estética entre Alemania y Japón, vid. Andreas Becker, «German-Japanese Propaganda and Preparation for the Second World War. Arnold Fancks and Mansaku Itami’s 'Die Tochter des Samurai/Atarashiki tsuchi' (1937) and 'Political Religion'» en el congreso coordinado por Marcos Centeno, Cinema Around the Axis, Valencia, Universidad, 14-12-2011; y «Setsuko Hara's Acting in the 1950s: a Comparative Analysis» en Andreas Becker y Kayo Adachi-Rabe, coords., Sintai/soma. Presentation of Bodies in Japanese Film, Frankfurt, Goete-Univesity, 25-7-2013. En este mismo congreso se presentaron otras conclusiones sobre la asimilación estética entre Estados Unidos y Japón - Marcos Centeno, «Embodying Contradictions of the Japanese Economic Miracle»- o entre República Checa y Japón: Kentarō Kawashima, "Comedy of passive body. Koji Yamamura’s animated film Kafka. A Country Doctor». 
puede observar un proceso inverso: los conceptos filosóficos occidentales también podrían haberse transformado como consecuencia de la subjetividad japonesa (Masaki Kondō, Simon Frisch, Duddley Andrew, Keiji Asanuma). ${ }^{47}$ El mismo Sérgei Eisenstein recurrió a la tradición artística japonesa en ciertas ocasiones para desarrollar su teoría del montaje. ${ }^{48}$ Después de contemplar una representación de teatro Kabuki recurre a varias de sus peculiaridades para reforzar su idea de la «atracción». ${ }^{49}$ Asimismo, recurrió a la poesía haiku para hablar de la «materia prima» del cine.

Dejando de lado las implicaciones que podría haber tenido para la ciencia semiótica haber incorporado la lingüística no indoeuropea -aunque hay intentos tardíos de estudios semióticos de la cultura desde la lingüística japonesa que surgen a partir de Barthes, como Yoshihiko Ikegami ${ }^{50}$-, la intención es señalar aquí el flujo de influencias teóricas en ambas direcciones. Los ejemplos de Eisenstein demuestran que lo nacional es una categoría en constante conflicto, rebatida en numerosas ocasiones y que tiende a fracasar. La dialéctica entre lo nacional y lo internacional cae víctima de su propia semejanza.

Como consecuencia, separar la teoría japonesa de la occidental es harto complejo, al igual que establecer categóricamente divisiones entre unos y otros cines. Debemos tener presente que en realidad, este cine tuvo la peculiaridad de nacer con posterioridad a la modernización de la Restaura-

47 Masaki Kondō, «The Impersonalization of the Self in an Image Society», Iris, 16 (1993): 37-49; Sobre la influencia de conceptos estéticos japoneses en el arte europeo, como por ejemplo el impresionismo, $c f r$. las aportaciones de Simon Frisch: «Die große Ausleerungsbewegung: Die Begegnung mit Japan in den europäischen Kulturen», en Mathias Mertens y Volker Wortmann, eds., Medien, Diskurs, Geschichte. Festschrift für Jan Berg. Salzhemmendorf, Blumenkamp, 2009: 189-221; o la presentación «Kire: Der Ab-geschnittene Körper im Film» en Andreas Becker y Kayo Adachi-Rabe, coords., Sintail soma... 2013.

48 Sergei Eisenstein, «Lo inesperado», en La forma del cine, Madrid, Siglo XXI, 2006 ${ }^{\text {aa }}$ : 2433. Recopilación de ensayos escritos entre 1928 y 1945, publicados originalmente en The Film Form, New York/London, HBJ, 1949.

49 Sobre cómo Eisenstein utiliza recursos estéticos de las artes tradicionales japonesas para desarrollar sus conceptos cinematográficos (montaje, atracciones, neutralización...) véase Andrew Duddley, The Major Film Theories, London, Oxford University Press, 1976; ed. en español: Las principales teorías cinematográficas. Madrid, Rialp, 1992: 71-89.

50 Yoshihiko Ikegami, «Homology of language and culture: A case study in Japanese semiotics», en Walter A. Koch, The Nature of Culture, Bochum, Brockmeyer, 1989: 388403; «DO-language and BECOME-language: Two contrasting types of linguistic representation», en Yoshihiko Ikegami, ed., The Empire of Sings: Semiotic Essays on Japanese Culture, Amsterdam, John Benjamins, 1991: 258-326. 
ción Meiji, en el momento en que Japón estaba abriéndose a la tecnología e ideas occidentales. Junto a la llegada del nuevo medio también debieron colarse conceptos occidentales. Pero estas ideas no se impusieron del todo a la tradición filosófica japonesa sino que se mezclaron con ella. Como han señalado diversos autores, encontramos una migración de términos, que al pasar por el tamizado de la tradición japonesa dieron lugar a conceptos en cierta medida, nuevos (Masaki Kondō, Simon Frisch, Duddley Andrew, Keiji Asanuma). Se produjo una contaminación de sentidos en el contexto local de llegada y se introdujeron matices nuevos hasta el punto de hacer que los mismos términos significaran cosas distintas en Occidente y Japón.

El uso del primero plano es un claro ejemplo. En alguna ocasión se ha señalado que el término en inglés close up, es una forma de expresión cultural no equivalente al japonés ōutsushi (Kenji Iwamoto). ${ }^{51}$ Mientras en Occidente connota una aproximación y hace más íntima la escena, en Japón incorpora el matiz de agrandamiento de un objeto, más que el acercamiento. El cine occidental ha asignado al primer plano la función de revelar el drama interior de los personajes, «no es otra cosa que una ventana al espíritu o corazón humano» (Béla Balázs). ${ }^{52}$ Por ello, se tiende recurrir a él en los momentos más dramáticos, sin embargo, el cine clásico de Mizoguchi, por ejemplo, se caracterizó por una estrategia opuesta: fomentar lo dramático con planos abiertos a través de largos planos secuencia.

Como ha señalado Iwamoto, los primeros planos están presentes en los patrones de representación occidentales y corresponde a una cosmovisión antropocéntrica del mundo de raíces muy antiguas. ${ }^{53}$ Sin embargo, en Japón, el sintoísmo y el budismo no privilegiaron tanto el papel central del hombre como su pertenencia a un todo en la naturaleza. Por ello, los planos abiertos de Mizoguchi no conectan con el clasicismo cinematográfico heredado de Griffith sino con prácticas culturales locales. Autores de la nouvelle vague francesa, principalmente Jean Luc-Godard tomaron prestados de Mizoguchi los largos planos secuencia de Mizoguchi, viendo en ellos un rasgo modernista del cine. Sin embargo, homólogos de la nueva ola japonesa como Susumu Hani desarrollaron una modernidad cinematográfica usando estos elementos del lenguaje fílmico en sentido contrario. Hani recurrió al primer plano para capturar el «espejo del alma» a través

51 Kenji Iwamoto, «Japanese Cinema Until 1930: A Consideration of its Formal Aspects», Iris, 16 (1993): 9-23.

52 Citado por Iwamoto, 1993: 12.

53 Iwamoto, 1993: 14-15. 

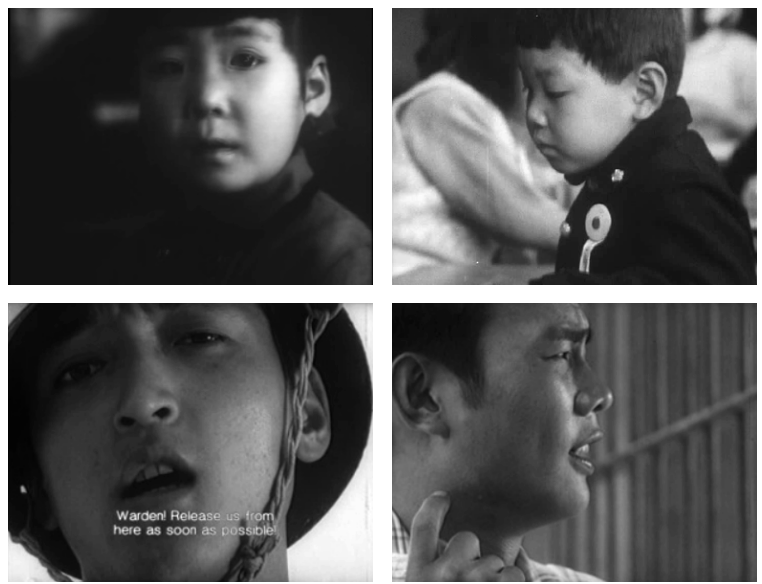

Children in the Classroom (Fig. 1), Children Who Draw (Fig.2), Bad Boys (Figs. 3 y 4 )

de las expresiones de los personajes, utilizándolo como una herramienta para profundizar en la psicología de los objetos filmados. ¿Qué papel juega entonces el primer plano en la historia del cine?

Las diferencias de partida entre los autores japoneses y occidentales condicionaron la manera de entender la modernidad cinematográfica. Mientras los correligionarios franceses privilegiarán los encuadres abiertos como reacción a la tradición estética europea, la nueva ola japonesa utiliza los planos cerrados como elementos rupturistas con su propia tradición. Por ello, los planos cerrados de Hani Masumura, Ōshima o Imamura, tienen sentido transgresor, pero para ello es necesario ubicarlos en el contexto japonés.

Otro ejemplo es el uso de los «planos secuencia». A diferencia del modelo euroamericano, Hani no recurre a ellos para reforzar el clímax o los momentos de tensión dramática que de hecho, rechaza en sus obras, sino para la espontaneidad de los gestos no controlados por el autor. Los planos secuencia le sirven como recurso para reducir el poder de influencia del director sobre el montaje. Estos hechos ponen de relieve la diferencia entre el concepto de «modernidad» occidental y su transliteración japonesa, modanizumu. A nivel narrativo, los largos planos secuencia de Hani suponen un desafío a las reglas del raccord. Pero a nivel formal, las largas tomas y travellings ya eran características en el cine de Mizoguchi. 
Esto nos devuelve al problema de la relatividad en la modernidad. Si las deliberadamente largas tomas de Truffaut o Godard eran irreverentes con la norma de montaje francés, las largas tomas de Hani no eran tan rupturistas con el montaje clásico japonés.

\section{Conclusión}

Aunque el desarrollo teórico sobre estos conceptos excede los límites este texto, lo que pretendemos es ilustrar que incluso en el análisis de la obra autores tan diversos como el clásico Ozu o el modernista Hani beben de numerosas influencias extranjeras pero a su vez, no se pueden obviar el peso del contexto cultural en el que desarrollaron sus obras. La incorporación de principios estéticos autóctonos podría contribuir a la mejor comprensión de su propia producción japonesa. Dicho esto, también debemos precisar que por un lado, los conceptos cinematográficos occidentales mutaron al introducirse en el contexto japonés. Por otro, los conceptos estéticos autóctonos no han permanecido inalterables, pues también han ido evolucionando con a partir del contacto con el pensamiento occidental a lo largo del tiempo. Al recurrir a ellos para el estudio de la imagen, especialmente al tratar la noción de japonesidad en el cine, debemos ser conscientes de su carácter híbrido y cambiante, lo cual abre nuevas vías para el estudio del cine japonés en su dimensión transnacional. El cine japonés nunca estuvo aislado ni fue ajeno a influencias extranjeras, pese a que el país desarrollara desde bien temprano una industria fílmica nacional propia. La idea del cine japonés como un cine nacional aislado y ligado a su tradición artística y estética fue construida desde occidente en base a una cuidadosa selección de films que se habían exportado a Occidente para triunfar en festivales de cine asombrando a la audiencia con imágenes exóticas de un Japón anclado en el pasado legendario y vinculado a su cultura tradicional. Sin embargo, incluso los grandes maestros utilizados para representar la supuesta japonesidad cinematográfica, Kurosawa, Ozu y Mizoguchi, se caracterizaron por renovar su cine nacional adaptando modos de representación narrativos y estéticos occidentales. Asimismo, el lenguaje cinematográfico se desarrolló con una rica combinación y transformación de conceptos originados en Occidente y Oriente, dando lugar a fenómenos cinematográficos híbridos y maleables. Esto demuestra como fue precisamente la impureza del cine japonés, su mestizaje con otras formas estético-narrativas, lo que dotó a su cine de una naturaleza singular, que si bien fue un fenómeno nacional, paradójicamente no se puede entender sin su carácter transnacional. 


\section{REFERENCIAS}

AlmazÁn, David, 2000, "Antes de Kurosawa: primeras noticias sobre el cine japonés en España», Studium. Revista de Humanidades, 7 (2000): 7-22.

ANDREW, Dudley y Michael RAINE, 1993, «Japanese Image Culture», Iris. Image Theory, Image Culture, and Contemporary Japan, 16 (1993): 3-9.

Asanuma, Keiji, 1993, «The Theory of Cinema and Traditional Aesthetic Thought of Japan», Iris, 16 (1993): 127-145.

BARretT, Gregory, 1989, Archetypes in Japanese Film. The Sociopolitical and Religious Significance of the Principal Heroes and Heroines. London, Associated University Press. (Edición de Oxford-New York, Oxford University Press, 2000).

BARThes, Roland, 1984, L'Émpire des signes. París, Flammarion, (tr. al español de Adolfo García Ortega, El imperio de los signos, Barcelona, Seix Barral, 2007).

Becker, Andreas, 2011, «German-Japanese Propaganda and Preparation for the Second World War. Arnold Fancks and Mansaku Itami's 'Die Tochter des Samurai/Atarashiki tsuchi' (1937) and 'Political Religion'». En Marcos Centeno, coord., Cinema Around the Axis. Valencia, Universidad, 14-12-2011 (congreso).

Becker, Andreas, 2013, «Setsuko Hara's Acting in the 1950s: a Comparative Analysis». En Andreas Becker y Kayo Adachi-Rabe, coords., Sintailsoma. Presentation of Bodies in Japanese Film, Frankfurt, Goete-Univesity, 25-72013 (congreso).

BecKer, Andreas, Kayo AdACHI-RABE y Florian MundHEnKe, eds, 2010, JapanEuropa. Wechselwirkungen zwsischen den Kulturen im Film den darstellenden Künsten (Japón-Europa. Interacciones entre la cultura del cine y las artes escénicas). Darmstadt, Büchner.

BORDwell, David y Kristin ThOMSON, 1976, «Space and Narrative in the Films of Ozu», Screen 17/2 (1976): 41-73.

Bordwell, David y Noël Carroll, eds., 1996, Post-theory: Reconstructing Film Studies. Madison, University of Wisconsin Press.

Bordwell, David, 1988, Ozu adn the Poetics of Cinema. Princeton, Princeton University Press.

Bordwell, David, 1994, Film history: an Introduction. New York, McGraw Hill.

Bourdieu, Pierre, 1993, «The Field of Cultural Production, or: The Economic

World Reversed». En The Field of Cultural Production. New York, Columbia University Press, 29-74.

BuRCH, Noël, 1979, To the distant observer: form and meaning in the Japanese cinema. Berkeley, University of California Press.

Centeno, Marcos, 2013, «Embodying Contradictions of the Japanese Economic Miracle». En Andreas Becker y Kayo Adachi-Rabe, coords., Sintailsoma. 
Presentation of Bodies in Japanese Film, Frankfurt, Goete-Univesity. (Congreso 25-07-2013).

CrofTs, Stephen, 1993, «Reconceptualizing National Cinema/s», Quarterly Review of Film and Video, 14/3 (1993): 49-67.

Desser, David, 1988, Eros Plus Massacre: An Introduction to The Japanese New Wave Cinema. Bloomington, Indiana University Press.

Dissanayake, Wimal y Rob Wilson, eds., 1996, Global/Local: Cultural Production and the Transnational Imaginary, Durham, Duke University Press.

Dissanayake, Wimal, 2013, «Narrative, Spectacle and Disruption: The Discourse of the Body in Takeshi Kitano's Zatōichi». En Andreas Becker y Kayo AdachiRabe, coords., Shintai/soma, Frankfurt, Goethe-Universität. Congreso celebrado el 25 y 26-07-2013.

Duddley, Andrew, 1976, The Major Film Theories. London, Oxford University Press. (Ed. en español: Las principales teorías cinematográficas. Madrid, Rialp, 1992).

EIsENSTEIn, Sergei, 1949, «Lo inesperado». En S. Eisenstein, La forma del cine, Madrid, Siglo XXI (2006 $\left.{ }^{7 a}\right)$ : 24-33.

Elsaesser, Thomas, 1989, New German Cinema: A History. Hampshire, British Film Institute.

FrisCH, Simon, 2009, «Die große Ausleerungsbewegung: Die Begegnung mit Japan in den europäischen Kulturen». En Mathias Mertens y Volker Wortmann, eds., Medien, Diskurs, Geschichte. Festschrift für Jan Berg. Salzhemmendorf, Blumenkamp, 2009: 189-221.

FuruHATA, Yuriko, 2007, «Returning to Actuality: Fūkeiron and the Landscape Film», Screen, 48/3 (2007): 345-362

Furuhata, Yuriko, 2009, Refiguring Actuality: Japan's Film Theory and Avant-Garde Documentary Movement 1950s-1960s, Ann Arbor, UMI, (tesis doctoral).

FuruhatA, Yuriko, 2013, Cinema of Actuality: Japanese Avant-garde Filmmaking in the Season of Image Politics. Durham, Duke University Press, 2013;

Gerow, Aaron, 1993, «Celluloid Masks: The Cinematic image and the Image of Japan», Iris, 16 (1993): 23-36.

Gerow, Aaron, 2010, «Introduction: The Theory Complex» y «The Process of Theory: Reading Gonda Yasunosuke and Early Film Theory», Review of Japanese Culture and Society, 22 (2010): 1-14 y 37-44. (Número especial: «Descentering Theory: Reconsidering the History of Japanese Film Theory»).

Giuglaris, Shinobu y Marcel Giuglaris, 1956, Le cinema japonais. Paris, du Cerf. (El cine japonés. Madrid, Rialp, 1957).

Higson, Andrew, 1989, «The Concept of National Cinema», Screen 30/4 (1989): $36-46$ 
Hiroshi, Kitamura, 2010, Screening Enlightenment. Hollywood and the Cultural Reconstruction of Defeated Japan, Ithaca, Cornell University Press.

HJORT, Mette, 2009, «Chapter 2. On the Plurality of Cinematic Transnationalism». En K. Newman \& N. Durovicova, eds., World Cinemas, Transnational Perspectives. London: Routledge/American Film Institute Reader: 12-31.

IkEgAmi, Yoshihiko, 1989, «Homology of language and culture: A case study in Japanese semiotics». En Walter A. Koch, The Nature of Culture. Bochum, Brockmeyer: 388-403;

IkEgAmI, Yoshihiko, 1991, «DO-language and BECOME-language: Two contrasting types of linguistic representation». En Yoshihiko Ikegami, ed., The Empire of Sings: Semiotic Essays on Japanese Culture. Amsterdam, John Benjamins: 258-326.

Iwamoтo, Kenji, 1987, «Film Criticism and the Study of Cinema in Japan: A Historical Survey», Iconics, 1 (1987): 129-146.

Iwamoтo, Kenji, 1993, «Japanese Cinema Until 1930: A Consideration of its Formal Aspects», Iris, 16 (1993): 9-23.

IWASAKI, Akira, 1931, Eiga to shibon shugi「映画と資本主義」(《Cine y capitalismo»), Tokio, Ōraisha.

KAWASHIMA, Kentarō, 2013, "Comedy of passive body. Koji Yamamura's animated film Kafka. A Country Doctor». En Andreas Becker y Kayo Adachi-Rabe, coords., Sintai/soma. Presentation of Bodies in Japanese Film, Frankfurt, Goete-Univesity, 25-7-2013 (congreso).

Kirihara, Donald, 1992, Patterns of Time: Mizoguchi and the 1930s. Madison, University of Wisconsin Press.

Kirihara, Donald, 1996, «Reconstructing Japanese Film». En David Bordwell y Noël Carroll, eds., Post-Theory: Reconstructing Film Studies. University of Wisconsin Press: 501-519;

KONDŌ, Masaki, 1993, "The Impersonalization of the Self in an Image Society», Iris, 16 (1993): 37-49.

KraCAUER, Siegfried, 1947, From Caligari to Hitler: A Psychological History of the German Film. New Jersey, Princeton University Press (tr. esp. de Héctor Grossi, De Caligari a Hitler: historia psicológica del cine alemán. Barcelona, Paidós, 1985).

MASAKI, Kondō, 1993, «The Impersonalization of the Self in an Image Society», Iris, 16 (1993): 37-49.

Nygren, Scott, 2007, Time Frames. Japanese Cinema and the Unfolding of History, Minneapolis, London, University of Minnesota Press.

Nornes, Abe-Mark, 2003, Japanese Documentary Film: The Meiji Era through Hiroshima, Minneapolis, University of Minnesota Press.

PRINCE, Stephen, 1991, Explorations in Film Theory: Selected Essays from CineTracs. Bloomington, Indiana University Press. 
PrinCE, Stephen, 1993, «The Discourse of Pictures: Iconicity and Film Studies», Film Quarterly, 47/1 (1993): 16-28.

Richie, Donald, 1974, Ozu: His Life and Films. Berkeley, University of California Press.

Rosen, Philip, 1984, «History, Textuality, Nation: Kracauer, Burch and Some Problems in the Study of National Cinemas», Iris 2/2 (1984): 17-28.

SADOUL, George, 1966, Histoire du cinéma mondial. Paris, Flammarion.

TANIZAKI, Junichirō, 1933-1934, «Inei raisan»「陰戨礼讃」, en Keizai ōrai. Tokio, Nihon hyōronsha, 12-1933 / 01-1934. (Traducción al español: El elogio de la sombra, Madrid, Siruela, 1994).

Tessier, Max, 1981, Images du cinéma japonais, Paris, Henry Veyrier.

UsuI, Michiko. «The Roots of Japanese Movies as Seen in the Tsubouchi Memorial Theatre Museum Collection", Yomiuri Shinbun. (http://www.yomiuri.co.jp/ $\mathrm{adv} / \mathrm{wol} / \mathrm{dy} /$ culture/080717.htm)

Weinrichter, Antonio, 2002, Pantalla amarilla: el cine japonés. Las Palmas de Gran Canaria, Festival Internacional de Cine.

Yамамото, Kikuo, 1983, Nihon eiga ni okern gaikoku eiga no eikyo ( La influencia del cine extranjero en el cine japonés»)「日本映画における外国映画の影響」, Tokyo, Waseda Daigaku Shuppanbu.

Yosнiмото, Mitsuhiro, 1993, «Le postmoderne et les images de masse au Japon», Iris, 16 (1993): 9-23. 
Notas / Notes 



\title{
STVDIVM 23 (2017)
}

\author{
Stvdivm. Revista de Humanidades \\ Zaragoza: Prensas de la Universidad de Zaragoza \\ Universidad de Zaragoza. ISSN: 1137-8417
}

\section{Notas / Notes}

Nota a la Historia de los nombres del diablo cartesiano de José Carrasquer, Adrián Ponz, M. ${ }^{a}$ Victoria Álvarez y Javier Uría, publicado en Studium. Revista de Humanidades, 19 (2013), págs. 75-96.

\section{José CARRASQueR ${ }^{1}$, María José GIL ${ }^{1}$, Adrián PONZ1, M. ${ }^{a}$ Victoria ÁlVAREZ ${ }^{1}$ J Javier URÍA ${ }^{2}$}

En un trabajo anterior publicado en esta revista (Carrasquer, Ponz, Álvarez y Uría, 2013) se revisaron los diversos nombres que ha recibido a lo largo de sus trescientos cincuenta años de existencia, el aparato físico denominado ludión o Diablo Cartesiano (DC). En el artículo se indicaron los orígenes de la mayoría de los nombres y los autores que los utilizaron por primera vez. Sin embargo en aquel momento, quienes suscribimos el estudio todavía no disponíamos de suficiente información para realizar una propuesta definitiva acerca del origen del nombre Diablo Cartesiano.

La máquina o aparato llamado diablo cartesiano recibió desde un principio diversas denominaciones y ha continuado así, posiblemente porque el nombre utilizado desde los ámbitos de la curandería o de la magia, DC,

1 Docentes e investigadores del Departamento de Didáctica de las Ciencias Experimentales de la Universidad de Zaragoza. Miembros del Grupo Consolidado de Investigación Aplicada Beagle del Gobierno de Aragón y la Universidad de Zaragoza y del Instituto Universitario de Investigación en Ciencias Ambientales (IUCA). Correos electrónicos: josecarr@unizar.es,quilez@unizar.es, adrian.ponz@unizar.es,valvarez@unizar.es.

2 Profesor e investigador del Área de Filología Latina, Departamento de Ciencias de la Antigüedad de la Universidad de Zaragoza. Correo electrónico: juria@unizar.es.

Fecha de recepción de la nota: 30 de octubre de 2017. Fecha de aceptación: 12 de diciembre de 2017. 
no fue aprobado por los ambientes cultos, ni por filósofos y naturalistas, ya que éstos no reconocían a Descartes como el inventor del aparato.

Si bien fue Raffaello Magiotti (1648) quien describió el funcionamiento físico de este aparato, será Teichmeyer (1712) el primero en denominarlo por escrito como DC; Wolff (1722) se refirió a él como Täucherlein, es decir pequeño buzo. La utilización de la denominación pequeño buzo y DC se difundió en los textos de Wolff y de sus traductores, así como en los de otros autores.

En su texto de física experimental, Wolff introdujo un capítulo titulado Von den Täucherlein, en uno de cuyos párrafos escribe:

[...] Ich nenne sie Täucherlein, weil sie sich im Wasser nach Gefallen untertauchen und wieder hervor kommen. Einige pflegen sie auch Diabolos Cartesianos oder Cartesianische Teuffel zu nennen und wie Teuffel machen zu lassen. (Wolff, 1722: 30).

[Yo los llamo los pequeños buceadores, porque se hunden en el agua y salen de nuevo a discreción. Algunos acostumbran a llamarlos Diabolos Cartesianos o diablo cartesiano y a hacerlos fabricar con forma de diablo.]

\section{Propuesta}

La denominación DC plantea un verdadero enigma desde el siglo XVIII: su origen y motivación parece haber sido desconocido incluso para los primeros autores que la utilizaron en textos escritos, pues la mencionan como designación secundaria utilizada por algunos, sin especificar:

— Ludwig Philipp Thümmig (1725: 271-272): [...] quos Diabolos Cartesianos nonnulli vocant («los que algunos llaman Diablos Cartesianos»).

— Christian Wolff, traducido por Jean Des Champs (1736: 136): [...] le petit Diable Cartésien, comme on l'appelle («el Diablillo Cartesiano, como se le llama»).

— Georg Wolfgang Krafft (1738: 277): [...] à nonnullis Diaboli Cartesiani vocentur hae imagines («estas figuras son llamadas por algunos Diablos Cartesianos»).

— Roberto Smith (1740: 223): [...] diabolos Cartesianos aliqui vocant («algunos llaman Diablos Cartesianos»).

— Samuel Christian Hollmann (1744: 239): [...] quos vocant Cartesiani («que llaman Cartesianos»).

— Georg Wolfgang Krafft (1761: 331): [...] imagunculae vitreae [...] vulgo Diaboli Cartesiani vocatae («figuritas de cristal [...] llamadas popularmente Diablos Cartesianos»). 
Ello invita a pensar que la expresión surgió fuera del ámbito culto, es decir, que no existió una autoridad académica que diera carta de naturaleza al giro, pues en ese caso es difícil que la bibliografía posterior no hiciera referencia a tal autoridad. Precisamente ese origen no culto puede dar la clave para comprender la motivación de esa locución, que habría sido de tipo popular.

Son diversas citas las que confirman que serían los agyrtae o circunvalatores los que utilizaban el aparato y le asignaban ese nombre:

Stutgardianum Thermoscopium, quod ex lagena vitrea, aquâ repleta, \& diabolo Cartesii vitreo cavo inmerso, constat, nullam amplius considerationem meretur inter haec instrumenta, quia frigus observationes impedit; nihilominus curiosum manet experimentum physicum, quo agyrtae imprimis ad imposturam utuntur. (Juch, 1735: 11).

[El termoscopio de Stuttgart, que consta de una botella de cristal llena de agua y de un diablo de Descartes de cristal hueco sumergido en ella, no merece mayor consideración entre estos instrumentos, porque el frío impide la observación; de todos formas sigue siendo un curioso experimento físico, que usan sobre todo los feriantes para engañar.]

Cum praesens Experimentum à circumforaneis quandoque adhiberi soleat ad fallendos imperitos, qui, verae causae naturalis inscii, virunculos hos circumforaneorum iussui, praestigiarum ope, parere putant : hinc factum est, vt à nonnullis Diaboli Cartesiani vocentur hae imagines, forsan ab inventore Cartesio. (Krafft, 1738, 277).

[Como este experimento es utilizado de vez en cuando por los charlatanes para engañar a los ingenuos, estos, ignorantes de la verdadera causa natural, creen que estos hombrecillos, por arte de magia, obedecen las órdenes de los charlatanes. De ahí surgió que algunos llamaran a estas figuras Diablos Cartesianos, quizás por su inventor Descartes.]

Partiendo de esta base, es decir, que el nombre proviniese del ambiente no culto y folklórico de los agyrtae o circunvalatores - que eran vagabundos, adivinadores del porvenir, sanadores o echadores de augurios-, cualquier planteamiento de un origen culto del término queda descartado y, en consecuencia, cualquier intento de indagar sobre un posible fundamento racional de la denominación, tendría que ser desestimado. Esta propuesta queda avalada por la gran cantidad de textos en los que se indica que no son los filósofos naturales los que utilizan esa denominación sino 'otros'; $y$, en multitud de ocasiones, los escritos también hacen referencia al uso vulgar o popular de diablo cartesiano.

Asimismo, el hecho comprobado de que en todos estos textos tampoco se indique el más mínimo indicio del origen, puede ratificar la idea de que 
en esos momentos históricos se desconocía el posible origen de la denominación. Es decir, que se sabía quién la empleaba, pero se desconocía cuál era el motivo de su utilización, aunque por ser tan habitual su uso, quedó recogida en sus textos.

\section{REFERENCIAS}

Carrasquer, José, Adrián Ponz, María Victoria Álvarez y Javier Uría, 2013, «Historia de los nombres del diablo cartesiano» Studium, Revista de Humanidades, 19 (2013): 75-96.

HollmanN, Samuel Christian, 1744, «Epistola de subitanea congelatione, de Igne electrico, de Micrometro Microscopio applicando». Philosophical transactions, XLIII: 239-249. http://rstl.royalsocietypublishing.org/content/43/475/239. full.pdf+html

JuCH, Hermann Paul, 1735, Instrumentis aerometricis eorumque usu in Medicina. Erfurt, Typis Heringii. 22 p.

KrafFT, Georg Wolfgang, 1738, Experimentorum Physicorum Praecipuorum. Brevis Descriptio, In Usum Auditorum Suorum. Petropoli, Typis Academiae. 277 p.

KraffT, Georg Wolfgang, 1761, Praelectiones Academicae Publicae in Physicam Theoreticam. Tubinga: Cotae.

Magiotti, Raffaello, 1648, Renitenza certissima dell' Acqua alla Compressione, Dichiarata con varij scherzi, in occasione d' altri Problemi curiosi. Roma: Francesco Moneta. 23 p.

SMITH, Roberto, 1740, «Praelectiones Hydrostaticae ac Pneumaticae, habita quondam a Rogero Cotesio». Nova Acta Eruditorum, (aprilis MDCCXL): 219-227. http://gallica.bnf.fr/ark:/12148/bpt6k50057z/f226.image

TeichmeYer, Hermann Friedrich, 1712, Amoenitates Philosophiae Naturalis. Jena: Sumptibus Autoris. $112 \mathrm{p}$.

ThüMmig, Ludwig Philipp, 1725, Institutiones Philosophiae Wolfianae in Usos Academicos. Vol. 1. Frankfurt: Libraria Rengeriana.

WolfF, Christian von, 1722, Allerhand Nützliche Versuche, Dadurch Zu genauer Erkäntnis Der Natur und Kunst Der Weg gebäbnet wird. Vol. 2. Halle-Magdeburg: Rengerischen Buchhandlung.

WolfF, Christian von, 1736, Logique Ou Réflexions Sur Les Forces De L'entendement Humain Et Sur Leur Legitime Usage, Dans La Connoissance De La Verite. Berlin: Haude. 266 p. 
Sumarios/Summaries 
